\title{
A point mutation in cPsE renders Streptococcus pneumoniae nonencapsulated and enhances its growth, adherence and competence
}

\author{
Thierry O Schaffner ${ }^{1,2}$, Jason Hinds ${ }^{3}$, Katherine A Gould ${ }^{3}$, Daniel Wüthrich ${ }^{2,4,5}$, Rémy Bruggmann ${ }^{4,5}$,
} Marianne Küffer ${ }^{1}$, Kathrin Mühlemann ${ }^{1,6^{\wedge}}$, Markus Hilty ${ }^{1,6^{\dagger}}$ and Lucy J Hathaway ${ }^{1 *+}$

\begin{abstract}
Background: The polysaccharide capsule is a major virulence factor of the important human pathogen Streptococcus pneumoniae. However, S. pneumoniae strains lacking capsule do occur.

Results: Here, we report a nasopharyngeal isolate of Streptococcus pneumoniae composed of a mixture of two phenotypes; one encapsulated (serotype 18C) and the other nonencapsulated, determined by serotyping, electron microscopy and fluorescence isothiocyanate dextran exclusion assay.

By whole genome sequencing, we demonstrated that the phenotypes differ by a single nucleotide base pair in capsular gene cpsE ( $C$ to $\mathrm{G}$ change at gene position 1135) predicted to result in amino acid change from arginine to glycine at position 379 , located in the cytoplasmic, enzymatically active, region of this transmembrane protein. This SNP is responsible for loss of capsule production as the phenotype is transferred with the capsule operon. The nonencapsulated variant is superior in growth in vitro and is also 117-fold more adherent to and more invasive into Detroit 562 human epithelial cells than the encapsulated variant.

Expression of six competence pathway genes and one competence-associated gene was 11 to 34-fold higher in the nonencapsulated variant than the encapsulated and transformation frequency was 3.7-fold greater.

Conclusions: We identified a new single point mutation in capsule gene cpsE of a clinical S. pneumoniae serotype $18 \mathrm{C}$ isolate sufficient to cause loss of capsule expression resulting in the co-existence of the encapsulated and nonencapsulated phenotype. The mutation caused phenotypic changes in growth, adherence to epithelial cells and transformability. Mutation in capsule gene cpsE may be a way for S. pneumoniae to lose its capsule and increase its colonization potential.
\end{abstract}

Keywords: Streptococcus pneumoniae, cpsE, Capsule, Nonencapsulated, SNP

\section{Background}

The Gram positive bacterium Streptococcus pneumoniae frequently colonizes the nasopharynx but can also invade the host causing serious illnesses such as pneumonia, meningitis or bacteraemia [1]. A principal virulence factor of S. pneumoniae is the polysaccharide capsule protecting it from host immune defences by interfering with the deposition of complement and therefore

\footnotetext{
* Correspondence: lucy.hathaway@ifik.unibe.ch

${ }^{\dagger}$ Equal contributors

Deceased

'Institute for Infectious Diseases, University of Bern, Friedbühlstrasse 51,

$\mathrm{CH}-3010$ Bern, Switzerland

Full list of author information is available at the end of the article
}

opsonophagocytosis [2-4]. The capsule is the target of all currently available pneumococcal vaccines including the 13-valent pneumococcal conjugate vaccine (PCV13) for children. The biochemical structure and linkage of repeating polysaccharide subunits determines the serotype of encapsulated strains. So far, more than 90 different serotypes have been identified [5-11] which differ in the type and number of genes encoding the proteins responsible for transcription, polymerization, elongation and export of the capsule. For almost all serotypes the capsule-encoding operon is located between non-capsule genes $\operatorname{dex} B$ and aliA $[6,12,13]$. The first four genes $\operatorname{cps} A$, cps $B, \operatorname{cps} C$ and $\operatorname{cps} D$ are thought to play a role in regulation 
of capsular production and are largely conserved between serotypes $[14,15]$.

Despite the importance of the capsule as a virulence factor, nonencapsulated pneumococci occur and in the nasopharynx may represent around $15 \%$ of pneumococcal isolates [16]. Nonencapsulated pneumococci are generally considered not to be virulent but are associated with outbreaks of conjunctivitis [17-19].

Although lacking the protection from opsonophagocytosis which a capsule affords, the absence of capsule may confer advantages. Nonencapsulated pneumococci are less sensitive to $\alpha$-defensins, elastase and cathepsin $\mathrm{G}$ of neutrophils, possibly due to the difference in their surface charge compared to encapsulated pneumococci $[16,20]$. Conversely, capsule might reduce agglutination by mucus, increasing access to epithelial cells and so aiding colonization, at least in mice [21] and may contribute to antibiotic tolerance [22].

However, laboratory-generated nonencapsulated mutants have shown that possession of a capsule is a burden for growth [23]. For pneumococci which do have a capsule, downregulation of its expression in response to the environment helps colonization by aiding adherence to respiratory epithelial cells [24].

Nonencapsulated S. pneumoniae may be divided into two groups: those which have aliB-like homologues or nspA gene in place of capsule genes and those which have a capsule operon very similar to that of an encapsulated strain [25-27]. For the latter, loss of capsule expression may be due to point mutations in capsule genes or spontaneous, reversible sequence duplication or non-reversible deletion within the capsule operon as described for serotypes 3, 8, 19F and 37 [28-33]. In the laboratory, nonencapsulated variants can be obtained by knocking out specific genes of the capsule operon. D39 mutants lacking capsule genes cps $2 K$, cpsJ or cps $2 H$ required suppressor mutations in cpsE (also denoted as wchA) to survive [34,35]. CpsE is the initial glycosyltransferase enzyme that catalyzes the transfer of the activated glucose-phosphate to the lipid carrier [36-40]. Previous research has shown that a functional CpsE protein is essential for encapsulation of pneumococci serotypes $9 \mathrm{~N}, 13,14,15 \mathrm{~B}$ and $19 \mathrm{~F}$ $[12,37,41]$.

During our studies of nasopharyngeal clinical isolates of pneumococci we observed an isolate which gave a mixture of larger smooth colonies (serotype 18C) and smaller rough colonies. We aimed to discover whether this was due to the presence of encapsulated and nonencapsulated versions of the same strain and, if so, to uncover the mechanism of the loss of capsule expression. We compared the two phenotypes in terms of growth, adherence to epithelial cells and competence for genetic transformation.

\section{Methods}

\section{Bacterial strains}

Streptococcus pneumoniae strain 307.14 (MLST 113) was isolated in Switzerland from the nasopharynx of a child with otitis media and determined to be serotype $18 \mathrm{C}$ by the Quellung reaction as previously described $[25,42]$.

A single colony from the nasopharyngeal swab was cultured in broth once before freezing the stock. Plating out of this stock showed that there were two 307.14 variants (encapsulated, nonencapsulated) which were purified by three consecutive passaging steps where each time one single colony was picked and streaked on a Columbia sheep blood agar (CSBA) plate. Separation was confirmed by serotyping and FITC-dextran exclusion assay (data not shown).

Serotyping was performed by Quellung reaction with serotype-specific antisera from the Statens Serum Institute (Copenhagen, Denmark).

Restriction fragment length polymorphism (RFLP) analysis was performed as described previously [43], with the following modifications, to confirm that the two phenotypes had the same genetic background. The initial denaturation step was performed for 4 minutes at $95^{\circ} \mathrm{C}$. Denaturation temperature was $95^{\circ} \mathrm{C}$ in the 30 cycles of PCR. Each reaction was performed in a total volume of $50 \mu \mathrm{l}$ with 3 units FastStart Taq DNA polymerase, $200 \mu \mathrm{M}$ deoxynucleoside triphosphates, $5 \mu \mathrm{l} 10 \times$ PCR reaction buffer (without $\mathrm{MgCl}_{2}$ ) and $2 \mathrm{mM} \mathrm{MgCl}_{2}$ (all from Roche, Switzerland), $1 \mu \mathrm{M}$ of each primer and $100 \mathrm{ng}$ genomic DNA. Endonucleases AflIII, ApoI, DdeI and MseI (New England Biolabs, MA, USA) were used for digestion of the PCR product according the manufacturer's instructions.

\section{Antibiotic susceptibilities}

Etest $^{\circ}$ strips (AB BIODISK, Solna, Sweden, distributed in Switzerland by bioMérieux) were used to determine the minimal inhibitory concentrations (MIC) for the different antibiotics according to current international recommendations (www.clsi.org). A sterile cotton swab was soaked in 0.5 McFarland of bacterial culture and then streaked on agar plates (Mueller Hinton with 5\% sheep blood). Ten minutes later, the Etest ${ }^{\circ}$ strips were applied on the agar plates which were then incubated for $24 \mathrm{~h}$ and $48 \mathrm{~h}$ at $37^{\circ} \mathrm{C}$ with $5 \% \mathrm{CO}_{2}$ atmosphere.

\section{Construction of revertant mutant strains}

Capsule switch mutant strains were generated for both the encapsulated and the nonencapsulated 307.14 wild type variant using a Janus cassette based on the published method [23]. As a first step, a Janus mutant was made from each of the wild type phenotypes. Next, the Janus mutant (nonencapsulated) derived from the encapsulated wild type was transformed with DNA from the 
nonencapsulated wild type strain to create the mutant 307.14 cap-. Also, the Janus mutant derived from the nonencapsulated wild type was transformed with DNA from the encapsulated wildtype strain to create the mutant 307.14 cap+. Wild type and mutant strains used in this study are listed in Table 1 and the amplification and sequencing primers are listed in Additional file 1: Table S1. Pneumococcal strain AmiA9 (a kind gift of Regine Hakenbeck, University of Kaiserslautern, Germany) that harbours the genotype $r p s L_{\mathrm{K} 56 \mathrm{~T}}$ conferring streptomycin resistance [44] served as template for $r p s L_{\mathrm{K} 56 \mathrm{~T}}$ amplification. PCR products were purified using the Wizard ${ }^{\circ} \mathrm{SV}$ Gel and PCR Clean-Up system (Promega, USA). Stocks of competent recipient 307.14 variants were prepared by growing them in brain heart infusion broth (BHI) (Becton Dickinson, USA) supplemented with $5 \%$ fetal bovine serum (FBS) (Merck, Germany) to mid-logarithmic phase (optical density $\left.\left(\mathrm{OD}_{600 \mathrm{~nm}}\right)=0.5-0.8\right)$ followed by a $1: 20$ subculture in tryptic soy broth (TSB) (Becton Dickinson), $\mathrm{pH} 7$ [45] to $\mathrm{OD}_{600 \mathrm{~nm}}=0.13$. Bacteria were harvested by centrifugation at $+4^{\circ} \mathrm{C}$ and resuspended in TSB, $\mathrm{pH} 8+15 \%$ glycerol (Sigma, USA) for storage at $-80^{\circ} \mathrm{C}$ until use. DNA was extracted using the QIAamp DNA Mini Kit (Qiagen, Germany) following the manufacturer's instructions. Transformation was based on a previous description [46] diluting $100 \mu \mathrm{l}$ of thawed competent bacteria in $900 \mu \mathrm{l}$ fresh TSB pH 8 supplemented with 200 ng competence stimulating peptide (CSP-1, PolyPeptide Laboratories, Strasbourg, France). Bacteria were cultured for $10 \mathrm{~min}$ at $37^{\circ} \mathrm{C}$ before $500 \mathrm{ng} r p s L_{\mathrm{K} 56 \mathrm{~T}}$ PCR product, $1 \mu \mathrm{g}$ dexB-JanusaliA PCR product or $2 \mu \mathrm{g}$ genomic DNA was added and the samples incubated $20-40 \mathrm{~min}$ at $30^{\circ} \mathrm{C}$ to induce competence fully, followed by $120 \mathrm{~min}$ incubation at $37^{\circ} \mathrm{C}$. Serial dilutions made in phosphate-buffered saline (PBS), $\mathrm{pH} 7.4$ were spread onto CSBA plates containing $300 \mu \mathrm{g} / \mathrm{ml}$ streptomycin and $500 \mu \mathrm{g} / \mathrm{ml}$ kanamycin and

Table 1 Wild type and mutant pneumococcal strains used

\begin{tabular}{|c|c|c|}
\hline Strain & Serotype & Origin/comment \\
\hline $\begin{array}{l}307.14 \\
\text { encapsulated }\end{array}$ & $18 \mathrm{C}$ & Nasopharyngeal isolate \\
\hline $\begin{array}{l}307.14 \\
\text { nonencapsulated }\end{array}$ & nonencapsulated & Nasopharyngeal isolate \\
\hline $\begin{array}{l}307.14 \Delta c p s: .: \\
\text { Janus }\end{array}$ & nonencapsulated & $\begin{array}{l}\text { Laboratory mutant: strain } 307.14 \\
\text { encapsulated which has had its } \\
\text { capsule operon replaced by a } \\
\text { Janus cassette }\end{array}$ \\
\hline 307.14 cap+ & $18 \mathrm{C}$ & $\begin{array}{l}\text { Capsule switch mutant: } 307.14 \\
\text { nonencapsulated which has had } \\
\text { its capsule operon replaced by } \\
\text { that of } 307.14 \text { encapsulated }\end{array}$ \\
\hline 307.14 cap- & nonencapsulated & $\begin{array}{l}\text { Capsule switch mutant: } 307.14 \\
\text { encapsulated which has had its } \\
\text { capsule operon replaced by that } \\
\text { of } 307.14 \text { nonencapsulated }\end{array}$ \\
\hline
\end{tabular}

incubated at $37^{\circ} \mathrm{C}$ with $5 \% \mathrm{CO}_{2}$ atmosphere overnight. Single colonies were subcultured on antibiotic selective CSBA plates prior to genomic DNA extraction and strain preservation at $-80^{\circ} \mathrm{C}$ (Technical Service Consultants Ltd., Heywood, UK). The serotype of the clinical isolates, the Janus mutants and the capsule switch mutants was confirmed by the Quellung reaction after transformation. Insertion of the Janus cassette and replacement and correct insertion of the donor capsule was confirmed by four control PCR (see Additional file 1: Table S1) using the iProof polymerase (Bio-Rad, USA). In order to confirm successful transfer of cpsE wt and cpsE mutated version, the PCR product was sequenced by Sanger sequencing. In addition, PCR and sequencing was also performed at the sites of 6 other SNPs found to differ in the wild type phenotypes to check that these were not transferred.

\section{Quantification of capsule}

Fluorescence isothiocyanate (FITC)-dextran exclusion assay

Capsule thickness was determined using fluorescence labeled dextran (2 $000 \mathrm{kDa}$, Sigma) based a published method $[47,48]$. Bacteria were cultured in $10 \mathrm{ml}$ Lacks [49-51], $20 \mathrm{mM}$ glucose to $\mathrm{OD}_{600 \mathrm{~nm}}=0.5$, centrifuged at $3000 \times \mathrm{g}$ for $5 \mathrm{~min}$ at room temperature, washed once with $10 \mathrm{ml}$ of chemically defined medium (CDM) (no sugars) and then resusupended in $10 \mathrm{ml} \mathrm{CDM} \mathrm{(no} \mathrm{sugars).}$ $800 \mu \mathrm{l}$ were subcultured in $20 \mathrm{ml} \mathrm{CDM}, \mathrm{pH} 7,5.5 \mathrm{mM}$ glucose and grown to $\mathrm{OD}_{600 \mathrm{~nm}}=0.25$. The bacteria were harvested by centrifugation and the pellet resuspended in $850 \mu \mathrm{l}$ pre-chilled phosphate-buffered saline (PBS), pH 7.4. Bacterial FITC-dextran samples were prepared and visualized using a 100x objective as described [23].

The zone of exclusion of FITC-dextran indicates the polysaccharide capsule thickness. The experiment was repeated three times on different days and a total of 15 pictures of the mixed culture (307.14 encapsulated and 307.14 nonencapsulated) were taken. The serotype was confirmed by Quellung reaction.

\section{Electron microscopy}

Bacteria were cultured as described above for the FITCdextran exclusion assay, grown to $\mathrm{OD}_{600 \mathrm{~nm}}$ of $0.2-0.25$ in CDM, pH 7, $5.5 \mathrm{mM}$ glucose and harvested by centrifugation. Serotype was confirmed by Quellung reaction after overnight incubation at $37^{\circ} \mathrm{C}$ with $5 \% \mathrm{CO}_{2}$ atmosphere on CSBA plates.

Bacteria were cryopreserved by high-pressure freezing as described before [52]. Acetone containing 2\% osmium tetroxide, $0.1 \%$ uranyl acetate, $0.2 \%$ ruthenium hexamine trichloride (RHT) and a total of $4 \% \mathrm{H}_{2} \mathrm{O}$ served as medium for freeze substitution. The RHT added improves capsule resolution [53]. Electron micrographs from cross-sectional bacterial preparations were taken at a magnification of $53000 \times$. The polysaccharide 
capsule thickness was measured perpendicular to the bacterial cell wall from at least 30 randomly selected bacterial cell bodies in 15 pictures using the free software ImageJ v1.45 l (National Institutes of Health, USA, http://imagej.nih.gov/ij). One to four measurements were taken at distinct positions of a given cell body.

\section{Growth assays}

Strains were streaked onto CSBA plates and incubated at $37^{\circ} \mathrm{C}$ in $5 \% \mathrm{CO}_{2}$ overnight and then subcultured in the semi-defined, nutritionally relatively rich Lacks medium [49-51] supplemented with $20 \mathrm{mM}$ glucose and with the following modifications: $14.7 \mathrm{mM} \mathrm{C}_{2} \mathrm{H}_{3} \mathrm{NaO}_{2}$. $3 \mathrm{H}_{2} \mathrm{O}, 5.41 \mu \mathrm{M} \mathrm{CaCl}_{2}, 0.89 \mu \mathrm{M} \mathrm{MnSO}{ }_{4} \cdot \mathrm{H}_{2} \mathrm{O}$ (all Merck, Germany) and $\geq 12800 \mathrm{U}$ catalase (Sigma, C40) per liter Lacks medium, no $\mathrm{NaC}_{2} \mathrm{H}_{3} \mathrm{O}_{2}$ and no bovine albumin. For growth assays, CDM [54] representing a nutritionally limited environment was used. Since $\mathrm{pH}$ may affect growth and competence, $\mathrm{CDM}$ was stabilized using Sørensen buffer $\left(\mathrm{KH}_{2} \mathrm{PO}_{4}, \mathrm{Na}_{2} \mathrm{HPO}_{4} \cdot 2 \mathrm{H}_{2} \mathrm{O}\right)$, pH 7 instead of doubledistilled water (Additional file 1: Table S2). Half-loopfuls of colonies were used to inoculate $10 \mathrm{ml}$ Lacks supplemented with $20 \mathrm{mM}$ glucose. The bacteria were grown to $\mathrm{OD}_{600 \mathrm{~nm}}$ of 0.5 and frozen at $-80^{\circ} \mathrm{C}$ in aliquots in $15 \%$ glycerol. Thawed bacterial suspensions were diluted in PBS pH 7.4 and plated on CSBA to determine the number of colony forming units (CFU) per ml the next day. The serotype was confirmed by Quellung reaction. For growth assays an inoculum of $5 \times 10^{7}$ CFUs was used for subculture in $20 \mathrm{ml}$ $\mathrm{CDM}, 5.5 \mathrm{mM}$ glucose. Bacteria were grown for 10 hours at $37^{\circ} \mathrm{C}$ in a water bath and the $\mathrm{OD}_{600 \mathrm{~nm}}$ measured every 30 minutes. Growth assays were repeated on three different days.

\section{Transformation frequency}

To compare transformation frequencies between the two phenotypes the bacteria were cultured as described for the FITC-dextran exclusion assay and grown to $\mathrm{OD}_{600}=0.15$ in CDM, $5.5 \mathrm{mM}$ glucose, $\mathrm{pH}$ 7. $0.5 \mathrm{ml}$ of the culture were transferred to $9.5 \mathrm{ml}$ TSB competence medium $\mathrm{pH} 8.0$ prewarmed to $30^{\circ} \mathrm{C}$ and incubated for $15 \mathrm{~min}$ at $30^{\circ} \mathrm{C}$. CSP- 1 was added to final concentration of $100 \mathrm{ng} / \mathrm{ml}$ and the culture incubated for $15 \mathrm{~min}$ at $30^{\circ} \mathrm{C} .1 \mu \mathrm{g}$ of chromosomal DNA from streptomycin resistant strain 104.37 (serotype 6B) was added and the culture incubated for $60 \mathrm{~min}$ at $30^{\circ} \mathrm{C}$, then for $120 \mathrm{~min}$ at $37^{\circ} \mathrm{C}$. Serial dilutions $(1: 20)$ in $\mathrm{PBS} \mathrm{pH} 7.4$ were plated onto CSBA plates with and without $300 \mu \mathrm{g} / \mathrm{ml}$ streptomycin. After overnight incubation the number of colonies was counted and the transformation frequency calculated. The serotype was confirmed by Quellung reaction.

\section{Adherence to and invasion of human epithelial cell line Detroit 562}

Detroit nasopharyngeal epithelial cells (ATCC-CCL-138) were cultured as described [55] in $1 \times$ minimum essential medium (MEM) containing $2 \mathrm{mM}$ L-glutamine, $8.9 \mathrm{mM}$ sodium bicarbonate, $1 \times$ MEM non-essential amino acids, $1 \mathrm{mM}$ sodium pyruvate (all Gibco by Life Technologies, USA), 10\% heat-inactivated fetal bovine serum (FBS) (Merck), $100 \mathrm{U} / \mathrm{ml}$ penicillin and $100 \mu \mathrm{g} / \mathrm{ml}$ streptomycin and grown until reaching complete confluence at $37^{\circ} \mathrm{C}$ in $5 \% \mathrm{CO}_{2}$. For adherence and invasion assays, $500 \mu \mathrm{l}$ culture medium (no antibiotics) with $3 \times 10^{5}$ cells was added per well of a 24-well tissue culture plate and incubated for 24 h. S. pneumoniae was grown as described for the FITCdextran exclusion assay in CDM, $5.5 \mathrm{mM}$ glucose, $\mathrm{pH} 7$ to mid- logarithmic phase $\left(\mathrm{OD}_{600 \mathrm{~nm}}=0.15\right.$ for 307.14 , encapsulated and $\mathrm{OD}_{600}=0.25$ for 307.14 , nonencapsulated) and $500 \mu \mathrm{l}$ cell culture medium (no FBS or antibiotics) with $0.9 \times 10^{7}$ bacteria were added to each well containing previously washed cells $(0.85 \% \mathrm{NaCl})$. The 24 -well plate was centrifuged at $423 \times \mathrm{g}$ for 5 minutes at room temperature. After incubation for $30 \mathrm{~min}$ at $37^{\circ} \mathrm{C}$ with $5 \% \mathrm{CO}_{2}$, the cells were washed five times with saline to remove non-adherent bacteria and trypsinized with $200 \mu \mathrm{l} 0.05 \%$ trypsin-EDTA (Gibco by Life Technologies). To determine the number of invasive bacteria, the gentamicin protection assay described earlier was followed and the cells co-cultured with bacteria for $3 \mathrm{~h}$ at $37^{\circ} \mathrm{C}$ with $5 \% \mathrm{CO}_{2}[55,56]$. The cells were washed five times with saline and $1 \mathrm{ml}$ fresh MEM with gentamicin sulfate salt $(200 \mu \mathrm{g} / \mathrm{ml}$, Sigma) was added to each well for a 2 h-incubation at $37^{\circ} \mathrm{C}$ to kill extracellular bacteria. After washing with saline and trypsinization as described above, the cells were lysed by addition of $1 \%$ saponin (Sigma) and incubation for 7 minutes at room temperature. Appropriate dilutions in PBS, pH 7.4 were plated onto CSBA plates and incubated overnight. The number of colony-forming units (CFUs) was determined using an automated colony counter [57]. Adherence and invasion potential of the bacteria was calculated as the proportion of recovered bacteria to the inoculum. The serotype was confirmed by Quellung reaction.

\section{Whole genome analysis of bacterial genomes Whole genome sequencing}

A barcoded fragment library with $400-500$ bp insert size using "TruSeq DNA TruSeq DNA Sample Preparation Kit" (Illumina Inc., USA) was prepared for both bacterial genomes. The samples were sequenced in one lane of an Illumina HiSeq 2000 (Illumina Inc.) together with 23 unrelated barcoded samples. This resulted in 10,276,620 paired-end reads $(2 \times 100 \mathrm{bp})$ for sample 307.14, encapsulated and $8,715,247$ paired-end reads $(2 \times 100 \mathrm{bp})$ for sample 307.14 , nonencapsulated. 


\section{De novo assembly}

The reads of the variants 307.14 nonencapsulated and 307.14 encapsulated were subjected to de novo assembly using SPAdes (version 2.4.0, kmer sizes = $33,55,67,81,91,93,95,97,99)$ [58]. Only scaffolds equal or longer than 500 bp were used for the further analyses. The assembly of 307.14 nonencapsulated resulted in 2088272 bp in 63 scaffolds and a n50 of 79979 bp. The assembly of 307.14 encapsulated resulted in $2083495 \mathrm{bp}$ in 69 scaffolds and a n50 of $71589 \mathrm{bp}$.

\section{Polymorphisms detection}

To detect assembly errors, for the assemblies of the strains 307.14 nonencapsulated and 307.14 encapsulated a remapping was performed using bowtie2 (version 2.0.0beta6, options: -N 1 -very-sensitive) [59]. Differences were detected using samtools (version 0.1.19, mpileup). To detect polymorphisms between the two strains, the reads of 307.14 nonencapsulated were mapped to the de novo assembly 307.14 encapsulated and vice versa. The mapping was performed using bowtie2 (version 2.0.0beta6, options: -N 1 -very-sensitive). Subsequently, polymorphisms of both mappings were determined using samtools (version 0.1.19, mpileup) [60].

\section{Gene expression assays \\ Microarray}

Bacteria were cultured as described for the adherence and invasion assay to mid-logarithmic phase in CDM, $5.5 \mathrm{mM}$ glucose, $\mathrm{pH}$ 7. Double volume of RNAprotect ${ }^{\circ}$ bacteria reagent (Qiagen, Germany) was added to the bacterial suspension to stop further transcription. The samples were vortexed, incubated for $5 \mathrm{~min}$ at room temperature and then centrifuged at $4500 \times \mathrm{g}$ for $10 \mathrm{~min}$ at $+4^{\circ} \mathrm{C}$. The RNA was extracted with the RNeasy ${ }^{\circ}$ Mini Kit (Qiagen) following the manufacturer's instructions using a Mickle vibratory tissue disintegrator (Mickle Laboratory Engineering Company Ltd., UK) for mechanical disruption of the bacteria. Contaminating DNA was removed using the DNA-free $e^{\text {Tw }}$ Kit (Life Technologies) as described by the manufacturer. RNA purity, concentration and quality/integrity were checked using with the NanoDrop spectrophotometer ND-1000 (Thermo Scientific, USA) and the RNA Nano 6000 kit for the Agilent 2100 bioanalyzer (Agilent Technologies, USA) following the manufacturer's instructions. The entire transcriptome was analyzed by microarray as follows. RNA samples were hybridised to the B $\mathrm{GG@S} \mathrm{SPv1.4.0} \mathrm{microarray}$ designed by the Bacterial Microarray Group at St. George's, University of London and manufactured on the Agilent SurePrint platform (Agilent Technologies). Labelled cDNA was prepared from $1 \mu \mathrm{g}$ total RNA using Cy3-dCTP (GE Healthcare, UK) and SuperScript
II reverse transcriptase with random hexamer primers (Life Technologies). Labelled cDNA was purified by Qiagen MinElute column, combined with $10 \times \mathrm{CGH}$ blocking agent and $2 \times \mathrm{Hi}-\mathrm{RPM}$ hybridisation buffer (Agilent Technologies) and heated at $95^{\circ} \mathrm{C}$ for $5 \mathrm{~min}$ prior to loading onto microarray slides which were incubated overnight in an Agilent rotating oven at $65^{\circ} \mathrm{C}$, $20 \mathrm{rpm}$. After hybridization, slides were washed for $5 \mathrm{~min}$ at room temperature with CGH Wash Buffer 1 and $1 \mathrm{~min}$ at $37^{\circ} \mathrm{C}$ with CGH Wash buffer 2 (Agilent Technologies) and scanned immediately, using an Agilent High Resolution Microarray Scanner, at 5 micron resolution, 100\% PMT. Scanned images were quantified using Feature Extraction software v 10.7.3.1 (Agilent Technologies) and statistical analysis of raw intensity data was performed in GeneSpring v12.1 (Agilent Technologies). Data for 3 independent biological replicate experiments were analysed. Data for each sample were normalized using a 75th percentile shift plus baseline normalized to the median of the related control sample for each biological replicate. Statistically significant $(\mathrm{p}<0.05)$ differences of more than 10-fold between the two strains were identified in an unpaired t-test with Benjamini and Hochberg false discovery rate correction.

\section{Real time RT-PCR}

Bacteria were cultured as described for EM in CDM, $5.5 \mathrm{mM}$ glucose, $\mathrm{pH} 7$ to mid-log phase. Double volume of RNAprotect ${ }^{\circ}$ bacteria reagent (Qiagen) was added. RNA was isolated and real-time RT- PCR performed as described previously to analyze expression of the first gene of the capsule operon, cpsA and competence gene $\operatorname{com} X$ [61]. The primer sequences for $\operatorname{com} X$ were: forward primer, 5' -TGT ATG AAG AAG TCC AAG GGA CTG T-3', reverse primer, 5'-GTA AGC AGA GCA TGC CTT CTT G-3' and probe 6-FAM-CCC ATA AAT GAA GGT AAT ATT-MGB_NFQ.

\section{Statistical analysis}

GraphPad Prism v6.03 software for Windows (www. graphpad.com) was used to perform the statistical analysis with the unpaired $t$ test with Welch's correction. $\mathrm{p} \leq 0.05$, two-tailed, was considered significant.

\section{Nucleotide sequence accession numbers}

The genome raw sequences of the Illumina runs are deposited in the short reads archive (http://www.ncbi. nlm.nih.gov/sra): 307.14, encapsulated (SRX485275) and 307.14, nonencapsulated (SRX485278). BioProject accession PRJNA241072 (http://www.ncbi.nlm.nih.gov/ bioproject/241072). 


\section{Results}

Clinical pneumococcal isolate 307.14 consists of two variants: one encapsulated and one nonencapsulated On plating the nasopharyngeal isolate 307.14 onto CSBA plates, a mixture of large and small colonies was observed. The large colonies made up approximately 50\% of the total and were serotyped as $18 \mathrm{C}$ (hereafter referred to as 307.14 encapsulated) whereas repeated attempts to type the small colonies led to the conclusion that they were nonencapsulated (hereafter referred to as 307.14 nonencapsulated). RFLP was performed on both phenotypes and confirmed that they were of the same genetic background (RFLP type 14, data not shown). Following subculture in CDM with $5.5 \mathrm{mM}$ glucose, the bacteria were exposed to FITC-dextran. Figure 1A shows that by fluorescence microscopy two distinct sizes of bacteria could be observed. Transmission electron microscopy (EM) showed that while the encapsulated bacteria expressed a thick polysaccharide capsule (Figure 1B) the nonencapsulated expressed no visible capsule (Figure 1C).

To test the stability of the two phenotypes, each purified wild type variant was streaked onto CSBA plates and passaged six times over ten days on CSBA plates followed by culture in Lacks medium with $20 \mathrm{mM}$ glucose on day 4 and day 9 of the experiment. Both phenotypes were stable as 307.14 encapsulated retained its capsule as determined by Quellung reaction and FITCdextran exclusion assay and 307.14 nonencapsulated also maintained its phenotype over the repeated passaging (data not shown).

\section{Loss of capsule expression is due to a single point mutation in gene cpsE}

Polymorphisms for each assembly of the Illumina reads with a quality score of at least $200 \times$ and that were not detected as assembly error in the remapping were further
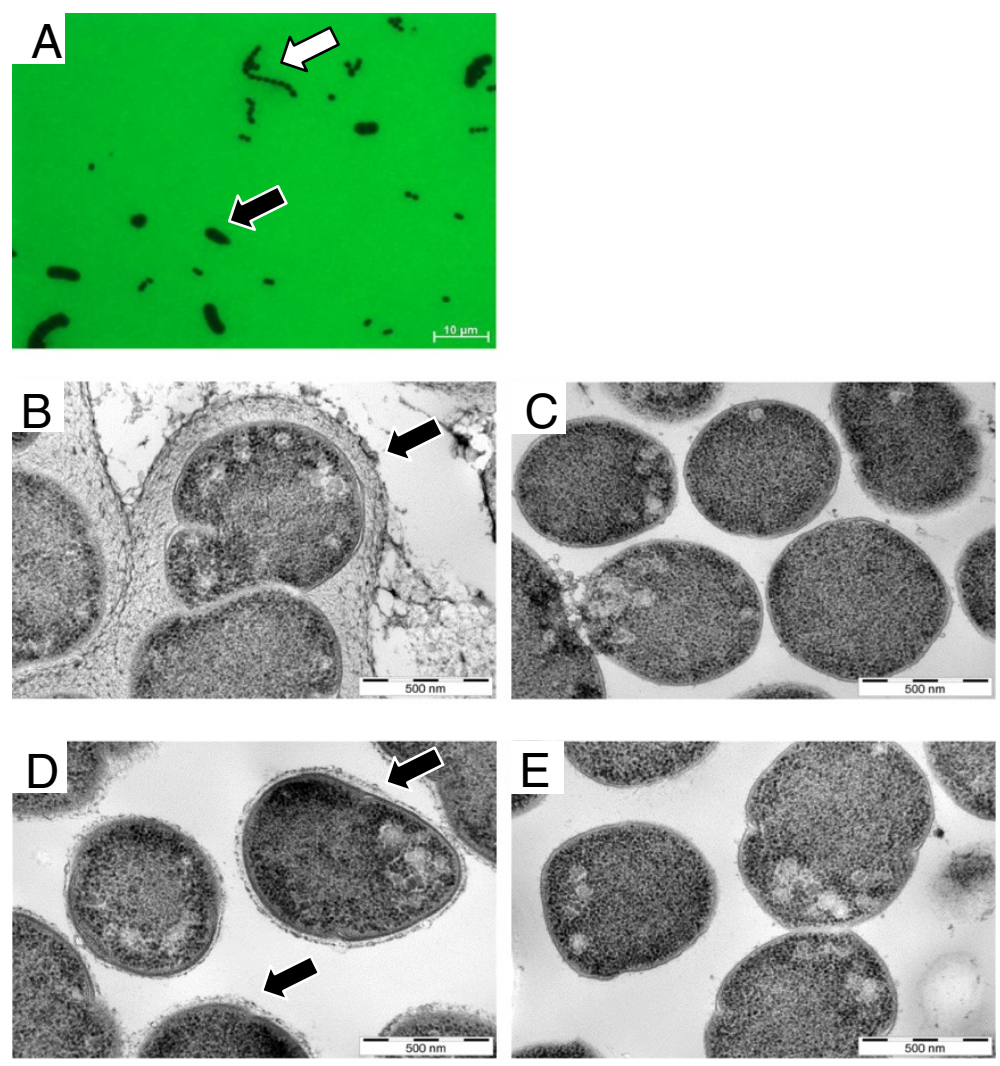

Figure 1 Nasopharyngeal pneumococcal isolate $\mathbf{3 0 7 . 1 4}$ is composed of encapsulated and nonencapsulated variants and the phenotype is transferred with the capsule operon. Strain 307.14 was cultured in CDM with $5.5 \mathrm{mM}$ glucose and viewed by (A) fluorescence microscopy in the presence of FITC-dextran (100x objective). The black arrow indicates pneumococci expressing a large amount of capsule, the white arrow indicates pneumococci expressing no capsule. The two phenotypes were subcultured separately and viewed by transmission electron microscopy (EM). (B) 307.14 encapsulated pneumococci expressing a thick polysaccharide capsule (indicated by the black arrow), (C) 307.14 nonencapsulated pneumococci expressing no visible capsule. Capsule switch mutants were created in which the capsule operons of the two phenotypes were exchanged. (D) "307.14 nonencapsulated" in which the operon has been replaced with that of "307.14 encapsulated" (creating mutant $307.14 \mathrm{cap}+$ ), expressing a thin capsule (marked with a black arrow). (E) "307.14 encapsulated" in which the operon has been replaced with that of "307.14 nonencapsulated" (creating mutant 307.14 cap-), expressing no detectable capsule. EM pictures (B) to (E) were taken at a magnification of $53000 \times$. 
analyzed. 7 single base pair differences (SNPs) between 307.14 encapsulated and 307.14 nonencapsulated were revealed (Table 2). One was a switch from cytosine to guanine at position 1135 of the capsule gene cpsE predicted to cause a switch from arginine to glycine at position 379 of the protein.

The role of this SNP in cpsE in loss of capsule expression was confirmed by exchanging the capsule operons between the encapsulated and nonencapsulated phenotypes. When the capsule operon of 307.14 nonencapsulated was replaced by that of 307.14 encapsulated the expression of an $18 \mathrm{C}$ capsule was acquired as determined by serotyping and electron microscopy (Figure 1D). We named this mutant 307.14 cap + (Table 1). However, expression was lower than in the natural encapsulated strain: The mean thickness of the polysaccharide capsule of 307.14 encapsulated was $137 \mathrm{~nm}$ and for $307.14 \mathrm{cap}+$ was $25 \mathrm{~nm}$. Likewise, replacing the capsule operon of 307.14 encapsulated with that of 307.14 nonencapsulated caused it to lose capsule as shown by electron microscopy (Figure 1E) and it became nontypeable by Quellung reaction. We named this mutant 307.14 cap- (Table 1). The six other SNPs identified by whole genome sequencing were not transferred (confirmed by sequencing, see Additional file 1: Table S1) confirming that the SNP in cpsE is sufficient alone to change the capsule phenotype.

\section{Effect of loss of capsule expression on growth}

Comparison of growth in vitro in a chemically defined medium (CDM) showed that the wild type 307.14

\begin{tabular}{|c|c|c|}
\hline $\begin{array}{l}\text { Gene product (TIGR4, } \\
\text { GenBank AE005672.3) }\end{array}$ & $\begin{array}{l}\text { SNP position in } \\
\text { gene }(307.14)\end{array}$ & $\begin{array}{l}\text { Base change } \\
\text { amino acid } \\
\text { change }\end{array}$ \\
\hline \multirow{2}{*}{$\begin{array}{l}\text { Undecaprenylphosphate } \\
\text { glucosephosphotransferase } \\
\text { (CpsE) (SP_0350) }\end{array}$} & \multirow[t]{2}{*}{1135} & $C \rightarrow G$ \\
\hline & & Arg $\rightarrow$ Gly \\
\hline \multirow{2}{*}{$\begin{array}{l}61 \text { bp upstream ABC transporter, } \\
\text { ATP-binding protein (SP_1282) }\end{array}$} & \multirow[t]{2}{*}{ not applicable } & $A \rightarrow G$ \\
\hline & & not applicable \\
\hline \multirow{2}{*}{$\begin{array}{l}\text { NOL1/NOP2/sun family } \\
\text { protein (SP_1402) }\end{array}$} & \multirow[t]{2}{*}{553} & $\mathrm{G} \rightarrow \mathrm{A}$ \\
\hline & & Asp $\rightarrow$ Asn \\
\hline \multirow{2}{*}{$\begin{array}{l}\text { Transposase, IS3 family, } \\
\text { degenerate (SP_2018) }\end{array}$} & \multirow[t]{2}{*}{ not applicable } & $\mathrm{T} \rightarrow \mathrm{G}$ \\
\hline & & not applicable \\
\hline \multirow[t]{2}{*}{ dlt B protein (SP_2175) } & \multirow[t]{2}{*}{449} & $A \rightarrow G$ \\
\hline & & Stop $\rightarrow$ Trp \\
\hline \multirow{2}{*}{$\begin{array}{l}\text { D-alanine-activating } \\
\text { enzyme (SP_2176) }\end{array}$} & \multirow[t]{2}{*}{514} & $A \rightarrow G$ \\
\hline & & Asn $\rightarrow$ Asp \\
\hline \multirow{2}{*}{$\begin{array}{l}\text { Translation elongation } \\
\text { factor Ts (SP_2214) }\end{array}$} & \multirow[t]{2}{*}{919} & $\mathrm{G} \rightarrow \mathrm{A}$ \\
\hline & & Glu $\rightarrow$ Lys \\
\hline
\end{tabular}

nonencapsulated, as well as the nonencapsulated laboratory mutant 307.14 $\Delta$ cps::Janus, had a clear growth advantage over 307.14 encapsulated (Figure 2). The lag phase of growth was shorter and the maximal $\mathrm{OD}_{600 \mathrm{~nm}}$ was higher for both of the nonencapsulated variants than the encapsulated (replicates shown in Additional file 1: Figure S1).

\section{Effect of loss of capsule on adherence and invasion}

For 307.14 encapsulated $1 \%$ of the inoculum adhered compared to $115 \%$ for 307.14 nonencapsulated. The relative value of adherent nonencapsulated 307.14 bacteria was presumably greater than $100 \%$ due to growth of the bacteria during the assay. This represents a 117fold greater adherence for the nonencapsulated phenotype compared to the encapsulated (Figure 3). Invasion of the epithelial cells was also greater for the nonencapsulated phenotype: $0.22 \%$ for 307.14 nonencapsulated and $0.0012 \%$ for 307.14 encapsulated, a difference of 183-fold reflecting the difference in adherence.

\section{Antibiotic susceptibility}

There were no significant differences in susceptibility of the two wild type variants to the antibiotics tested: ampicillin, benzylpenicillin, ceftriaxone, cephalothin, vancomycin, rifampicin, gentamicin, minocycline, tetracycline and colistin (Additional file 1: Table S3).

\section{Comparison of gene expression between encapsulated and nonencapsulated variants}

Gene expression was investigated by microarray which showed that 307.14 encapsulated and 307.14 nonencapsulated expressed the genes of the capsule operon to an equal extent. This was confirmed for the first gene of the capsule operon, cpsA, by real-time RT-PCR (data not shown). However, seven other genes were upregulated in 307.14 nonencapsulated compared to 307.14 encapsulated between 11 and 34-fold (Table 3). For one of the genes, $\operatorname{com} X$, expression was also determined by realtime RT-PCR by three independent experiments, each in triplicate. Comparing expression to that in the wild type encapsulated strain, a mean 3 fold higher expression was found in the wild type nonencapsulated strain, 35 fold higher in the 307.14 cap- mutant (differing from the wild type by only the SNP in cpsE) and 52 fold in the Janus mutant which lacks the entire capsule operon. Using the student $t$ test with Welch's correction these differences are not statistically significant, but the finding that nonencapsulated variants have a higher expression of $\operatorname{com} X$ than the encapsulated was consistent and in agreement with the microarray results. Strikingly, all seven genes identified by microarray were linked to competence, prompting us to compare the transformation frequencies between the variants. 307.14 encapsulated showed a mean 


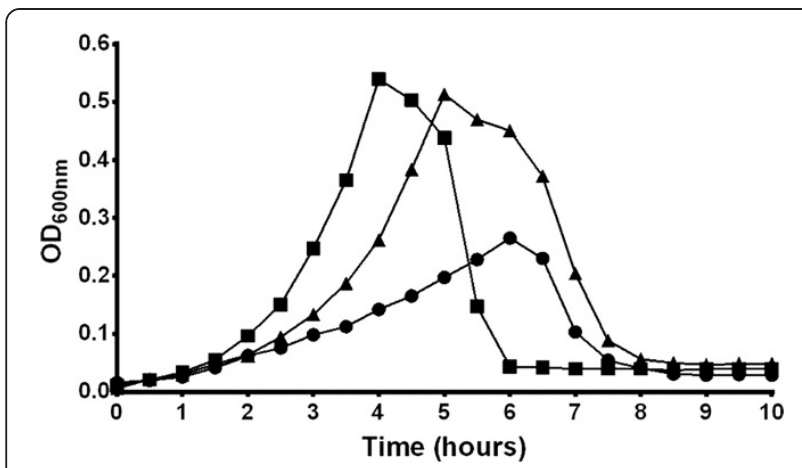

Figure 2 Nonencapsulated variant of strain $\mathbf{3 0 7 . 1 4}$ has an advantage over the encapsulated variant in growth. Growth was measured in vitro in CDM with $5.5 \mathrm{mM}$ glucose by determining $\mathrm{OD}_{600 \mathrm{~nm}}$ over 10 hours. Results show a representative of three independent experiments (see Additional file 1: Figure S1 for replicates). Wild type 307.14 encapsulated $(\bullet)$, wild type 307.14

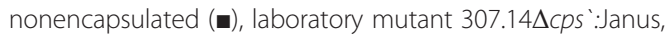
nonencapsulated $(\mathbf{\Lambda})$.

transformation frequency of $0.0328 \%$ and 307.14 nonencapsulated of $0.1216 \%$ (Figure 4). This represents a 3.7 -fold greater transformation frequency by the nonencapsulated variant compared to the encapsulated variant $(\mathrm{p} \leq 0.05)$. Expression of no other genes differed significantly between the encapsulated and nonencapsulated phenotypes.

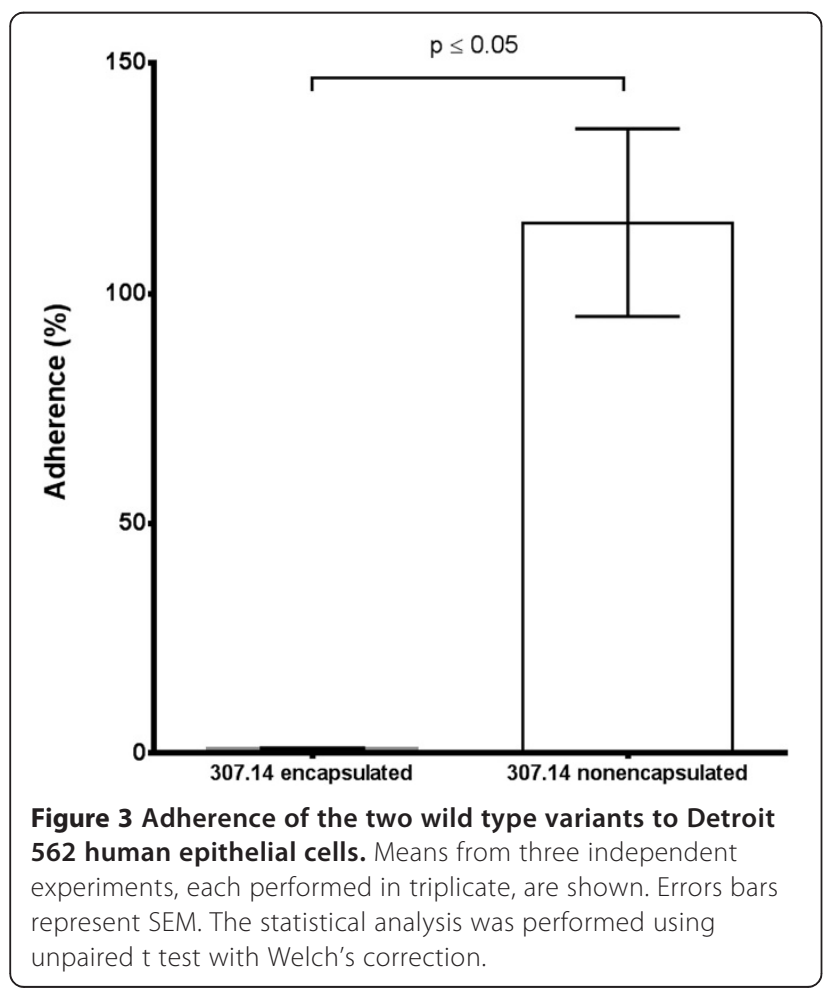

\section{Discussion}

Large and small pneumococcal colonies obtained from the nasopharynx of a child suffering from otitis media were due to two different patterns of capsule expression by one strain. The large colonies were due to bacteria expressing a thick capsule of serotype $18 \mathrm{C}$ and the small colonies were due to bacteria producing no detectable capsule. The difference was due to a single point mutation in the capsule gene cpsE. The resulting loss of capsule expression had clear consequences resulting in increased bacterial growth, adherence to epithelial cells and competence for genetic transformation. We speculate that the mutation occurred in vivo because the isolate contained an approximately 1:1 ratio of the encapsulated and nonencapsulated phenotypes. This is unlikely to have been achieved during the brief single laboratory culture before freezing the sample. We therefore conclude that the original colony derived directly from the patient contained a mixture of the encapsulated and nonencapsulated phenotypes.

Mutations in cpsE have been shown previously to lead to loss of capsule expression in clinical isolates. In 2012, Melchiorre et al., reported two pneumococcal isolates from patients with bacteraemic pneumonia. These isolates were nonencapsulated but with capsule operons very similar to those of serotype $7 \mathrm{~F}$ strains. The isolates had two distinct point mutations in cpsE both resulting in premature termination of transcription, CpsE which was truncated at the $C$ terminus and loss of encapsulation in these two strains [62]. CpsE is the initial glycosyltransferase responsible for the addition of activated glucose-phosphate to the lipid carrier in the bacterial membrane [36-40]. Laboratory-generated cpsE knock-out mutants are also nonencapsulated [12]. Here it appears that an encapsulated and nonencapsulated phenotype can coexist in the nasopharynx. It is also the first time a naturallyoccurring mutation in cpsE leading to loss of capsule expression has been described in a serotype $18 \mathrm{C}$ strain. Unlike the SNP described by Melchiorre et al., the SNP described here does not result in a premature stop codon but rather an amino acid change from arginine to glycine. In addition, the location of the SNP differs from those described previously $[34,35,62]$. Our data suggest that the amino acid at position 379 in the cytoplasmic $\mathrm{C}$ terminal region of $\mathrm{CpsE}$ is critical for the function of the protein and therefore polysaccharide capsule production. cpsE is the first serotype specific gene following the conserved genes $\operatorname{cps} A$ to $\operatorname{cps} D[14,15]$. However, there is high sequence similarity of cpsE gene throughout the serotypes $[12,37-41,63,64]$ which raises the possibility that SNPs in cpsE may be a more general phenomenon to control capsule expression in other serotypes. This mechanism seems to be irreversible in contrast to the previously described mechanism of loss of capsule expression by 
Table 3 Microarray analysis showing upregulation of gene expression in $\mathbf{3 0 7 . 1 4}$ nonencapsulated versus 307.14 encapsulated phenotype

\begin{tabular}{lll}
\hline Gene & Function & $\begin{array}{l}\text { Fold upregulation in } \\
\text { nonencapsulated }\end{array}$ \\
\hline comA & competence & 24 \\
comB & competence & 27 \\
comD & competence & 11 \\
comE & competence & 12 \\
comW & competence & 22 \\
comX & competence & 15 \\
orf51 & competence-induced bacteriocin B & 34 \\
\hline
\end{tabular}

spontaneous sequence duplication in the capsule operon $[29,30]$. Its irreversible nature, the apparent complete loss of capsule in the nontypeable phenotype and the fact that the two phenotypes did not vary in their expression of virulence gene such as $n a n A, h y l A, p s p A$ and $\operatorname{cbp} A$ differentiate the phenomenon we describe here from transparent/opaque phase variation $[65,66]$.

We have shown before that loss of capsule affects phenotype, especially growth [23] and others have shown that a loss of capsule is associated with a gain in adherence to epithelial cells [67]. However, in our previous publication we used laboratory-generated capsule mutants in which the capsule operon was deleted and replaced by a Janus cassette. Here we show that in a nonencapsulated mutant that has lost its capsule naturally in vivo we also see the same effect i.e. an enhancement of growth.

Transformation is an important feature of the pneumococcus and does occur in its natural human environment

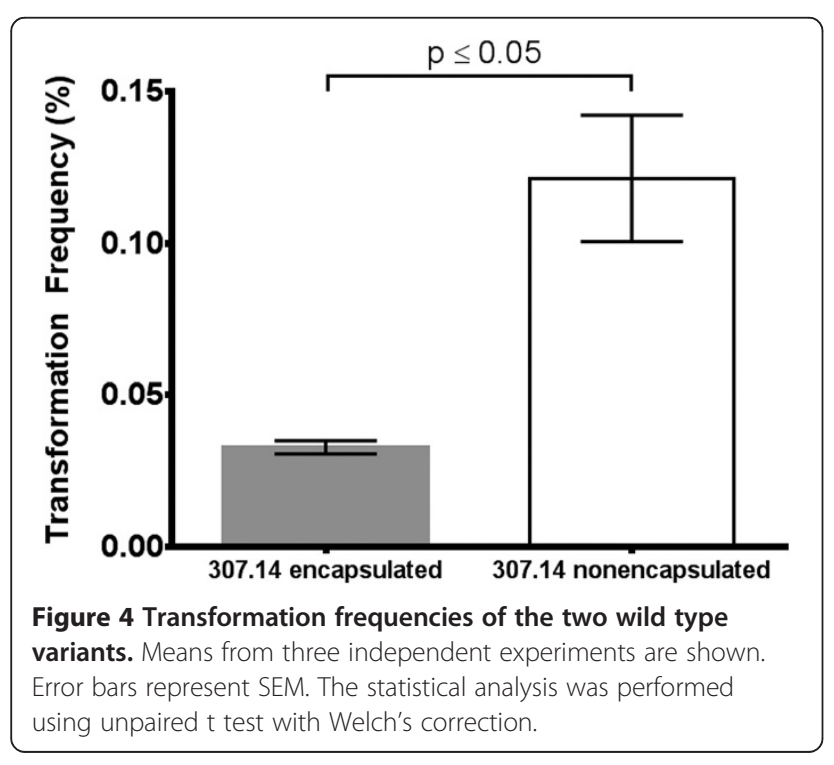

[68]. Nonencapsulated strains are known to be more transformable than encapsulated strains [69] but our results indicate that this is not only due to a loss of the barrier of the capsule but also to an upregulation of genes involved in the competence pathway. Four temporally distinct expression profiles have been described in competence: early, late and delayed gene induction, and gene repression [70]. We noted with interest that the nonencapsulated phenotype had a higher expression of only the early competence genes compared to the encapsulated phenotype. Upregulation of early competence genes has been observed in tissue infections such as pneumonia and meningitis, but not sepsis, and may be linked to the pneumococci being in a biofilm-like state [71]. Whether the nonencapsulated phenotype described here is more often associated with biofilm than the encapsulated phenotype remains to be investigated.

We did not find a difference in antibiotic susceptibility between the two phenotypes. Fernebro et al. have shown that capsule expression reduces antibioticinduced lysis however here we measured antibiotic resistance by Etest ${ }^{\oplus}$ and did not attempt to compare lytic responses [22].

A limitation of our study is that our isolate was from one patient at one timepoint. Although the fact that the two phenotypes were found at a ratio of approximately 1:1 suggests that they can co-exist in vivo, we do not know whether over time one phenotype would out-compete the other. We speculate that the nonencapsulated variant would have an advantage in colonization due to better growth and adherence and also be more able to take up foreign DNA (such as antibiotic resistance genes) giving it an advantage but we would need to make a study over time to determine this.

\section{Conclusions}

We conclude that $c p s E$ is critical for capsule expression in multiple serotypes. Mixtures of large and small colonies often seen in diagnostic laboratories and interpreted to be a mixture of strains could alternatively be a mixture of an encapsulated strain and its naturallyoccurring nonencapsulated mutant. The link between loss of capsule expression and increased transformability may be due not only to a loss of the capsule barrier but also due to an upregulation of expression of genes of the competence pathway.

\section{Availability of supporting data}

The data sets supporting the results of this article are included within the article and its additional files. 


\section{Additional file}

Additional file 1: Figure S1. Nonencapsulated variant of strain 307.14 has an advantage over the encapsulated variant in growth. This figure shows two replicates ( $A$ and $B$ ) of Figure 2. Growth was measured in vitro in CDM with $5.5 \mathrm{mM}$ glucose by determining $\mathrm{OD}_{600 \mathrm{~nm}}$ over 10 hours. Wild type 307.14 encapsulated (•), wild type 307.14 nonencapsulated (घ), laboratory mutant 307.14 $\Delta$ cps:Janus, nonencapsulated ( $\boldsymbol{\Delta}$ ). Table S1: Amplification and Sequencing Primers. Table S2: Preparation of the chemically defined medium (CDM). Table S3: Antibiotic susceptibilities. Minimal inhibitory concentrations (MIC) of the two S. pneumoniae 307.14 wild type variants to selected antibiotics determined by Etest ${ }^{\oplus}$ after $24 \mathrm{~h}$ and $48 \mathrm{~h}$ of incubation at $37^{\circ} \mathrm{C}$ and $5 \% \mathrm{CO}_{2}$ atmosphere.

\section{Abbreviations}

BHI: Brain heart infusion; bp: Base pairs; CDM: Chemically defined medium; CSBA: Columbia sheep blood agar; CSP-1: Competence-stimulating peptide; EM: Electron microscopy; FBS: Fetal bovine serum; FITC: Fluorescence isothiocyanate; MLST: Multi-locus sequence typing; PBS: Phosphate-buffered saline; RFLP: Restriction fragment length polymorphism; RHT: Ruthenium hexamine trichloride; SNP: Single nucleotide polymorphism; TSB: Tryptic soy broth.

\section{Competing interests}

The authors declare that they have no competing interests.

\section{Authors' contributions}

TOS, KAG, DW and MK performed the laboratory work, TOS, KM, MH and $\mathrm{LH}$ conceived the study, JH and RB participated in the study design and coordination. TOS, JH, KAG, DW, MH and LH wrote the manuscript. All authors read and approved the final manuscript.

\section{Acknowledgments}

We thank Suzanne Aebi, Simon Lüthi and Chantal Studer for excellent technical assistance and Siegfried Hapfelmeier for critical review of the manuscript.

Electron microscopy sample preparation and imaging were performed with devices supported by the Microscopy Imaging Centre (MIC) of the University of Bern.

This work was supported by a grant from the Swiss National Science Foundation (31003A_133157/1) to K.M. and currently led by L.J.H.

\section{Author details}

${ }^{1}$ Institute for Infectious Diseases, University of Bern, Friedbühlstrasse 51, CH-3010 Bern, Switzerland. ${ }^{2}$ Graduate School for Cellular and Biomedical Sciences, University of Bern, Bern, Switzerland. ${ }^{3}$ Bacterial Microarray Group at St George's (BuG@S), Division of Clinical Sciences, St George's, University of London, London, United Kingdom. ${ }^{4}$ Interfaculty Bioinformatics Unit, University of Bern, Bern, Switzerland. ${ }^{5}$ Swiss Institute of Bioinformatics, Lausanne, Switzerland. ${ }^{6}$ Department of Infectious Diseases, University Hospital of Bern, Bern, Switzerland.

Received: 29 April 2014 Accepted: 21 July 2014

Published: 28 August 2014

\section{References}

1. Austrian R: The pneumococcus at the millennium: not down, not out. J Infect Dis 1999, 179(Suppl 2):S338-S341.

2. Winkelstein JA, Abramovitz AS, Tomasz A: Activation of C3 via the alternative complement pathway results in fixation of $\mathrm{C} 3 \mathrm{~b}$ to the pneumococcal cell wall. J Immunol 1980, 124(5):2502-2506.

3. Brown EJ, Joiner KA, Cole RM, Berger M: Localization of complement component 3 on Streptococcus pneumoniae: anti-capsular antibody causes complement deposition on the pneumococcal capsule. Infect Immun 1983, 39(1):403-409.

4. Abeyta M, Hardy GG, Yother J: Genetic alteration of capsule type but not PspA type affects accessibility of surface-bound complement and surface antigens of Streptococcus pneumoniae. Infect Immun 2003, 71(1):218-225.

5. Henrichsen J: Six newly recognized types of Streptococcus pneumoniae. Clin Microbiol 1995, 33(10):2759-2762.
6. Bentley SD, Aanensen DM, Mavroidi A, Saunders D, Rabbinowitsch E, Collins M, Donohoe K, Harris D, Murphy L, Quail MA, Samuel G, Skovsted IC, Kaltoft MS, Barrell B, Reeves PR, Parkhill J, Spratt BG: Genetic analysis of the capsular biosynthetic locus from all 90 pneumococcal serotypes. PLoS Genet 2006, 2(3):e31.

7. Park IH, Park S, Hollingshead SK, Nahm MH: Genetic basis for the new pneumococcal serotype, 6C. Infect Immun 2007, 75(9):4482-4489.

8. Jin P, Kong F, Xiao M, Oftadeh S, Zhou F, Liu C, Russell F, Gilbert GL: First report of putative Streptococcus pneumoniae serotype 6D among nasopharyngeal isolates from Fijian children. J Infect Dis 2009, 200(9):1375-1380.

9. Bratcher PE, Kim KH, Kang JH, Hong JY, Nahm MH: Identification of natural pneumococcal isolates expressing serotype $6 \mathrm{D}$ by genetic, biochemical and serological characterization. Microbiol 2010, 156(Pt 2):555-560.

10. Calix JJ, Nahm MH: A new pneumococcal serotype, $11 \mathrm{E}$, has a variably inactivated wcjE gene. J Infect Dis 2010, 202(1):29-38.

11. Calix JJ, Porambo RJ, Brady AM, Larson TR, Yother J, Abeygunwardana C, $\mathrm{Nahm} \mathrm{MH:} \mathrm{Biochemical,} \mathrm{genetic,} \mathrm{and} \mathrm{serological} \mathrm{characterization} \mathrm{of}$ two capsule subtypes among Streptococcus pneumoniae Serotype 20 strains: discovery of a new pneumococcal serotype. J Biol Chem 2012, 287(33):27885-27894.

12. Kolkman MA, van der Zeijst BA, Nuijten PJ: Diversity of capsular polysaccharide synthesis gene clusters in Streptococcus pneumoniae. J Biochem 1998, 123(5):937-945

13. Garcia E, Llull D, Munoz R, Mollerach M, Lopez R: Current trends in capsular polysaccharide biosynthesis of Streptococcus pneumoniae. Res Microbiol 2000, 151(6):429-435.

14. Morona JK, Paton JC, Miller DC, Morona R: Tyrosine phosphorylation of CpsD negatively regulates capsular polysaccharide biosynthesis in Streptococcus pneumoniae. Mol Microbiol 2000, 35(6):1431-1442.

15. Morona JK, Miller DC, Morona R, Paton JC: The effect that mutations in the conserved capsular polysaccharide biosynthesis genes $\operatorname{cps} A, \operatorname{cps} B$, and cpsD have on virulence of Streptococcus pneumoniae. J Infect Dis 2004, 189(10):1905-1913.

16. van der Windt D, Bootsma HJ, Burghout P, van der Gaast-de Jongh CE, Hermans PW, van der Flier M: Nonencapsulated Streptococcus pneumoniae resists extracellular human neutrophil elastase- and cathepsin G-mediated killing. FEMS Immunol Med Microbiol 2012, 66(3):445-448.

17. Martin M, Turco JH, Zegans ME, Facklam RR, Sodha S, Elliott JA, Pryor JH, Beall B, Erdman DD, Baumgartner YY, Sanchez PA, Schwartzman JD, Montero J, Schuchat A, Whitney CG: An outbreak of conjunctivitis due to atypical Streptococcus pneumoniae. N Engl J Med 2003, 348(12):1112-1121.

18. Crum NF, Barrozo CP, Chapman FA, Ryan MA, Russell KL: An outbreak of conjunctivitis due to a novel unencapsulated Streptococcus pneumoniae among military trainees. Clin Infect Dis 2004, 39(8):1148-1154.

19. Porat N, Greenberg D, Givon-Lavi N, Shuval DS, Trefler R, Segev O, Hanage WP, Dagan R: The important role of nontypable Streptococcus pneumoniae international clones in acute conjunctivitis. J Infect Dis 2006, 194(5):689-696.

20. Beiter K, Wartha F, Hurwitz R, Normark S, Zychlinsky A, Henriques-Normark B: The capsule sensitizes Streptococcus pneumoniae to alpha-defensins human neutrophil proteins 1 to 3. Infect Immun 2008, 76(8):3710-3716.

21. Nelson AL, Roche AM, Gould JM, Chim K, Ratner AJ, Weiser JN: Capsule enhances pneumococcal colonization by limiting mucus-mediated clearance. Infect Immun 2007, 75(1):83-90

22. Fernebro J, Andersson I, Sublett J, Morfeldt E, Novak R, Tuomanen E, Normark S, Normark BH: Capsular expression in Streptococcus pneumoniae negatively affects spontaneous and antibiotic-induced lysis and contributes to antibiotic tolerance. J Infect Dis 2004, 189(2):328-338,

23. Hathaway LJ, Brugger SD, Morand B, Bangert M, Rotzetter JU, Hauser C, Graber WA, Gore S, Kadioglu A, Muhlemann K: Capsule type of Streptococcus pneumoniae determines growth phenotype. PLOS Pathog 2012, 8(3):e1002574.

24. Hammerschmidt S, Wolff S, Hocke A, Rosseau S, Muller E, Rohde M: Illustration of pneumococcal polysaccharide capsule during adherence and invasion of epithelial cells. Infect Immun 2005, 73(8):4653-4667.

25. Hathaway LJ, Stutzmann Meier P, Battig P, Aebi S, Muhlemann K: A homologue of aliB is found in the capsule region of nonencapsulated Streptococcus pneumoniae. J Bacteriol 2004, 186(12):3721-3729.

26. Salter SJ, Hinds J, Gould KA, Lambertsen L, Hanage WP, Antonio M, Turner P, Hermans PW, Bootsma HJ, O'Brien KL, Bentley SD: Variation at the 
capsule locus, cps, of mistyped and non-typable Streptococcus pneumoniae isolates. Microbiol 2012, 158(Pt 6):1560-1569.

27. Hanage WP, Kaijalainen T, Saukkoriipi A, Rickcord JL, Spratt BG: A successful, diverse disease-associated lineage of nontypeable pneumococci that has lost the capsular biosynthesis locus. J Clin Microbiol 2006, 44(3):743-749.

28. Arrecubieta C, Lopez R, Garcia E: Molecular characterization of cap3A, a gene from the operon required for the synthesis of the capsule of Streptococcus pneumoniae type 3: sequencing of mutations responsible for the unencapsulated phenotype and localization of the capsular cluster on the pneumococcal chromosome. J Bacteriol 1994, 176(20):6375-6383.

29. Waite RD, Struthers JK, Dowson CG: Spontaneous sequence duplication within an open reading frame of the pneumococcal type 3 capsule locus causes high-frequency phase variation. Mol Microbiol 2001, 42(5):1223-1232.

30. Waite RD, Penfold DW, Struthers JK, Dowson CG: Spontaneous sequence duplications within capsule genes cap8E and tts control phase variation in Streptococcus pneumoniae serotypes 8 and 37. Microbiol 2003, 149(Pt 2):497-504

31. McEllistrem MC, Ransford JV, Khan SA: Characterization of in vitro biofilm-associated pneumococcal phase variants of a clinically relevant serotype 3 clone. J Clin Microbiol 2007, 45(1):97-101.

32. Allegrucci $M$, Sauer $K$ : Characterization of colony morphology variants isolated from Streptococcus pneumoniae biofilms. J Bacteriol 2007, 189(5):2030-2038.

33. Allegrucci M, Sauer K: Formation of Streptococcus pneumoniae non-phase-variable colony variants is due to increased mutation frequency present under biofilm growth conditions. J Bacterio/ 2008, 190(19):6330-6339.

34. Xayarath B, Yother J: Mutations blocking side chain assembly, polymerization, or transport of a Wzy-dependent Streptococcus pneumoniae capsule are lethal in the absence of suppressor mutations and can affect polymer transfer to the cell wall. J Bacteriol 2007, 189(9):3369-3381.

35. James DB, Gupta K, Hauser JR, Yother J: Biochemical activities of Streptococcus pneumoniae serotype 2 capsular glycosyltransferases and significance of suppressor mutations affecting the initiating glycosyltransferase Cps2E. J Bacterio/ 2013, 195(24):5469-5478.

36. Cartee RT, Forsee WT, Bender MH, Ambrose KD, Yother J: CpsE from type 2 Streptococcus pneumoniae catalyzes the reversible addition of glucose-1-phosphate to a polyprenyl phosphate acceptor, initiating type 2 capsule repeat unit formation. J Bacteriol 2005 187(21):7425-7433

37. Kolkman MA, Morrison DA, Van Der Zeijst BA, Nuijten PJ: The capsule polysaccharide synthesis locus of Streptococcus pneumoniae serotype 14: Identification of the glycosyl transferase gene cps14E. J Bacteriol 1996, 178(13):3736-3741

38. Pelosi L, Boumedienne M, Saksouk N, Geiselmann J, Geremia RA: The glucosyl-1-phosphate transferase WchA (Cap8E) primes the capsular polysaccharide repeat unit biosynthesis of Streptococcus pneumoniae serotype 8. Biochem Biophys Res Commun 2005, 327(3):857-865.

39. van Selm S, Kolkman MA, van der Zeijst BA, Zwaagstra KA, Gaastra W, van Putten JP: Organization and characterization of the capsule biosynthesis locus of Streptococcus pneumoniae serotype $9 \mathrm{~V}$. Microbiol 2002, 148(Pt 6):1747-1755.

40. Jiang SM, Wang L, Reeves PR: Molecular characterization of Streptococcus pneumoniae type $4,6 \mathrm{~B}, 8$, and $18 \mathrm{C}$ capsular polysaccharide gene clusters. Infect Immun 2001, 69(3):1244-1255.

41. Guidolin A, Morona JK, Morona R, Hansman D, Paton JC: Nucleotide sequence analysis of genes essential for capsular polysaccharide biosynthesis in Streptococcus pneumoniae type 19 F. Infect Immun 1994, 62(12):5384-5396.

42. Kronenberg A, Zucs P, Droz S, Muhlemann K: Distribution and invasiveness of Streptococcus pneumoniae serotypes in Switzerland, a country with low antibiotic selection pressure, from 2001 to 2004. J Clin Microbiol 2006, 44(6):2032-2038.

43. Hathaway LJ, Brugger S, Martynova A, Aebi S, Muhlemann K: Use of the Agilent 2100 bioanalyzer for rapid and reproducible molecular typing of Streptococcus pneumoniae. J Clin Microbiol 2007, 45(3):803-809.

44. Salles C, Creancier L, Claverys JP, Mejean V: The high level streptomycin resistance gene from Streptococcus pneumoniae is a homologue of the ribosomal protein 512 gene from Escherichia coli. Nucleic Acids Res 1992, 20(22):6103.

45. Pozzi G, Masala L, lannelli F, Manganelli R, Havarstein LS, Piccoli L, Simon D, Morrison DA: Competence for genetic transformation in encapsulated strains of Streptococcus pneumoniae: two allelic variants of the peptide pheromone. J Bacteriol 1996, 178(20):6087-6090

46. Meier PS, Utz S, Aebi S, Muhlemann K: Low-level resistance to rifampin in Streptococcus pneumoniae. Antimicrob Agents Chemother 2003, 47(3):863-868

47. Gates MA, Thorkildson P, Kozel TR: Molecular architecture of the Cryptococcus neoformans capsule. Mol Microbiol 2004, 52(1):13-24.

48. Weinberger DM, Trzcinski K, Lu YJ, Bogaert D, Brandes A, Galagan J, Anderson PW, Malley R, Lipsitch M: Pneumococcal capsular polysaccharide structure predicts serotype prevalence. PLOS Pathog 2009, 5(6):e1000476.

49. Adams MH, Roe AS: A partially defined medium for cultivation of pneumococcus. J Bacteriol 1945, 49(4):401-409.

50. Lacks S, Hotchkiss RD: A study of the genetic material determining an enzyme in Pneumococcus. Biochim Biophys Acta 1960, 39:508-518.

51. Lacks S: Integration efficiency and genetic recombination in pneumococcal transformation. Genetics 1966, 53(1):207-235.

52. Studer D, Graber W, Al-Amoudi A, Eggli P: A new approach for cryofixation by high-pressure freezing. J MicrosC 2001, 203(Pt 3):285-294.

53. Hunziker EB, Graber W: Differential extraction of proteoglycans from cartilage tissue matrix compartments in isotonic buffer salt solutions and commercial tissue-culture media. J Histochem Cytochem 1986, 34(9):1149-1153.

54. van de Rijn I, Kessler RE: Growth characteristics of group A streptococci in a new chemically defined medium. Infect Immun 1980, 27(2):444-448.

55. Luer S, Troller R, Jetter M, Spaniol V, Aebi C: Topical curcumin can inhibit deleterious effects of upper respiratory tract bacteria on human oropharyngeal cells in vitro: potential role for patients with cancer therapy induced mucositis? Support Care Cancer 2011, 19(6):799-806.

56. Spaniol V, Heiniger N, Troller R, Aebi C: Outer membrane protein UspA and lipooligosaccharide are involved in invasion of human epithelial cells by Moraxella catarrhalis. Microbes Infect 2008, 10(1):3-11.

57. Brugger SD, Baumberger $C$, Jost M, Jenni W, Brugger U, Muhlemann K: Automated counting of bacterial colony forming units on agar plates. PLoS One 2012, 7(3):e33695.

58. Bankevich A, Nurk $S$, Antipov D, Gurevich AA, Dvorkin M, Kulikov AS, Lesin VM, Nikolenko SI, Pham S, Prjibelski AD, Pyshkin AV, Sirotkin AV, Vyahhi N, Tesler G, Alekseyev MA, Pevzner PA: SPAdes: a new genome assembly algorithm and its applications to single-cell sequencing. J Comput Biol 2012, 19(5):455-477.

59. Langmead B, Salzberg SL: Fast gapped-read alignment with Bowtie 2. Nat Methods 2012, 9(4):357-359.

60. Li H, Handsaker B, Wysoker A, Fennell T, Ruan J, Homer N, Marth G, Abecasis G, Durbin R, Genome Project Data Processing S: The sequence alignment/ Map format and SAMtools. Bioinform 2009, 25(16):2078-2079.

61. Hathaway $L$, Battig $P$, Muhlemann $K:$ In vitro expression of the first capsule gene of Streptococcus pneumoniae, $\cos A$, is associated with serotype-specific colonization prevalence and invasiveness. Microbiol 2007, 153(Pt 8):2465-2471.

62. Melchiorre S, Camilli R, Pietrantoni A, Moschioni M, Berti F, Del Grosso M, Superti F, Barocchi MA, Pantosti A: Point mutations in wchA are responsible for the non-typability of two invasive Streptococcus pneumoniae isolates. Microbiol 2012, 158(Pt 2):338-344.

63. Iannelli F, Pearce BJ, Pozzi G: The type 2 capsule locus of Streptococcus pneumoniae. J Bacteriol 1999, 181(8):2652-2654.

64. Morona JK, Morona R, Paton JC: Analysis of the $5^{\prime}$ portion of the type 19A capsule locus identifies two classes of $c p s C, c p s D$, and $c p s E$ genes in Streptococcus pneumoniae. J Bacteriol 1999, 181(11):3599-3605.

65. Weiser JN, Austrian R, Sreenivasan PK, Masure HR: Phase variation in pneumococcal opacity: relationship between colonial morphology and nasopharyngeal colonization. Infect Immun 1994, 62(6):2582-2589.

66. Li-Korotky HS, Lo CY, Banks JM: Interaction of pneumococcal phase variation, host and pressure/gas composition: virulence expression of NanA, HylA, PspA and CbpA in simulated otitis media. Microb Pathog 2010, 49(4):204-210.

67. Cundell DR, Weiser JN, Shen J, Young A, Tuomanen El: Relationship between colonial morphology and adherence of Streptococcus pneumoniae. Infect Immun 1995, 63(3):757-761. 
68. Ottolenghi-Nightingale E: Competence of pneumococcal isolates and bacterial transformations in man. Infect Immun 1972, 6(5):785-792.

69. Weiser JN, Kapoor M: Effect of intrastrain variation in the amount of capsular polysaccharide on genetic transformation of Streptococcus pneumoniae: implications for virulence studies of encapsulated strains. Infect Immun 1999, 67(7):3690-3692.

70. Peterson SN, Sung CK, Cline R, Desai BV, Snesrud EC, Luo P, Walling J, Li H, Mintz M, Tsegaye G, Burr PC, Do Y, Ahn S, Gilbert J, Fleischmann RD,

Morrison DA: Identification of competence pheromone responsive genes in Streptococcus pneumoniae by use of DNA microarrays. Mol Microbiol 2004, 51(4):1051-1070.

71. Oggioni MR, Trappetti C, Kadioglu A, Cassone M, lannelli F, Ricci S, Andrew PW, Pozzi G: Switch from planktonic to sessile life: a major event in pneumococcal pathogenesis. Mol Microbiol 2006, 61(5):1196-1210.

doi:10.1186/s12866-014-0210-x

Cite this article as: Schaffner et al:: A point mutation in cpsE renders

Streptococcus pneumoniae nonencapsulated and enhances its growth, adherence and competence. BMC Microbiology 2014 14:210.

\section{Submit your next manuscript to BioMed Central and take full advantage of:}

- Convenient online submission

- Thorough peer review

- No space constraints or color figure charges

- Immediate publication on acceptance

- Inclusion in PubMed, CAS, Scopus and Google Scholar

- Research which is freely available for redistribution 